\title{
Effects of Mn doping on dielectric properties of ferroelectric relaxor PLZT ceramics
}

\author{
V. Dimza, A.I. Popov*, L. Lāce, M. Kundzins, K. Kundzins, M. Antonova, M. Livins \\ Institute of Solid State Physics, University of Latvia, 8 Kengaraga Str, LV-1063 Riga, Latvia
}

Keywords:

PLZT

Ferroelectrics

Mn impurity

Dielectric properties

Impurities in perovskites

Point defects

\begin{abstract}
A B S T R A C T
A series of PLZT (8/65/35) ceramics with different $\mathrm{Mn}_{2} \mathrm{O}_{3}$ concentration $(0.01,0.1,0.3,1.0$, and $3.0 \%$ by weight) have been synthesized to figure out its influence on their dielectric properties. The complex dielectric permittivity $\varepsilon^{*}=\varepsilon^{\prime}-\mathrm{i} \varepsilon^{\prime \prime}$ as function of frequency and temperature as well as polarisation loops $\mathrm{P}(E)$ have been studied as a function of Mn concentration.

It was found that Mn doping is restrained the Vogel-Fulcher law held in the unmodified PLZT compound producing essential change of the dependence of $\varepsilon^{*}$ on temperature and frequency and of the shape of $\mathrm{P}(E)$. The observed effects are explained by gradual involvement of Debye and Maxwell-Wagner polarisation mechanisms in relaxation processes with the growth of the concentration of Mn concentration admixture. A decrease of the $\varepsilon^{\prime}(T)$ maximum value and shift of the maximum to higher temperatures is observed.

The observed effects are attributed to impacts of $\mathrm{Mn}^{2+}$ and $\mathrm{Mn}^{3+}$ ions: formation of oxygen vacancies paired with $\mathrm{Mn}^{2+}$ as dipoles and Jahn-Teller distortion prompted by $\mathrm{Mn}^{3+}$ ions.
\end{abstract}

\section{Introduction}

Perovskite oxide materials have attracted widespread scientific and technological interest for several decades because of their various extraordinary functional properties [1-10].

Among them, lanthanum-doped lead zirconium titanate ferroelectric compounds $\mathrm{Pb}_{1-y} \mathrm{La}_{\mathrm{y}} \mathrm{Zr}_{\mathrm{x}} \mathrm{Ti}_{1-\mathrm{x}} \mathrm{O}_{3}$ (PLZT) are very interesting because of their high optical transparency important in various optical applications such as light shutters, electro-optical modulators, color filters, memories and imaging storage devices [11-19].

The special interest is preparation of PLZT in the form of thin films [20-26]. The PLZT films prepared on ITO-coated glass were reported to possess good dielectric and electrooptic properties [21].

Two of the well-known ways to tailor the functional properties of the perovskite compounds includes introduction of the 3d-ions in their cation sites [27-38] or even by introduction of oxygen vacancies [39-42].

Note that, oxygen vacancies as well as their complexes with $3 d$ impurity ions, by introducing lattice distortions and charge carriers, show a strong impact on structural and electronic properties, such

\footnotetext{
* Corresponding author.

E-mail address: popov@latnet.lv (A.I. Popov).
}

as optical spectroscopy, phase transitions, ionic conductivity, and resistance switching [36,38-46].

In the case PLZT relaxor ceramics, the appropriate number of the studies, concerning their doping with d-compounds, is still very limited [47-50]. Special attention in these studies has been paid to the effects caused by admixtures, when the material properties are improved and/or deliberately modified as well as due to the interest in fundamental problems such as emergence of Jahn-Teller (JT) effect (JTE) [27,33,34,44].

Most common and well studied 3d metal (Me) admixtures in the most studied perovskites $\left(\mathrm{SrTiO}_{3}, \mathrm{BaTiO}_{3}\right.$, PZT etc) are $\mathrm{Mn}, \mathrm{Fe}$, $\mathrm{Co}$, and $\mathrm{Cu}$. It is assumed that the Me 3d-admixtures, with valence less than 4 , are localized in the $\mathrm{B}$ sites $\left(\mathrm{Ti}^{4+}, \mathrm{Ti}^{4+}\right)$ and induce formation of oxygen vacancies. The existence of Me- $V_{O}\left(V_{O}\right.$ - oxygen vacancy) pairs in the $\mathrm{ABO}_{3}$ compounds has been confirmed by EPR studies $[28,35]$.

However, the actual role of Me- $\mathrm{V}_{\mathrm{O}}$ pairs is still controversial in interpretations of experimental results the most interesting of which being two:

1) as dipoles, the Me- $V_{O}$ may be pronounced in Debye and/or Maxwell-Wagner relaxations [35,51,and52]. Within a single experiment in a limited frequency range it is not easy to make a distinction between the two types of relaxation [51] while 
experiments in the frequency range from zero to infinity is a challenge;

2 ) the presence of Me- $V_{O}$ pairs may cause defects of crystallographic shear (CS) [52]. In general, in nonstoichiometric materials for interpretation the Maxwell-Wagner polarisation, a crystallographic shear plane defects or superlattice effects can play a quite decisive role $[53,54]$.

None of the problems in PLZT ceramics have been practically studied. Recently, the effects of $\mathrm{Mn}, \mathrm{Fe}, \mathrm{Co}$, $\mathrm{Ni}$ and $\mathrm{Cu}$ admixtures on the structure and dielectric properties of PLZT ceramics were reported, but only at one concentration of $1 \mathrm{wt} \%$ [47] and no dopant concentration dependences were reported.

Note, that recently it has been shown and quantitatively confirmed that PLZT 8/65/35 ceramics can be considered as model classical relaxor compound [55].

In this report, a series of PLZT (8/65/35) ceramics with different $\mathrm{Mn}_{2} \mathrm{O}_{3}$ concentration $(0.01,0.1,0.3,1.0$, and $3.0 \%$ by weight) have been synthesized to figure out its influence on their dielectric properties. The emphasis is placed on the influence of Mn concentration on both the complex dielectric permittivity $\varepsilon^{*}=\varepsilon^{\prime}-\mathrm{i} \varepsilon^{\prime \prime}$ as function of frequency and temperature as well as polarisation loops $\mathrm{P}(E)$.

\section{Samples and experimental procedure}

The samples of PLZT (8/65/35) ceramics were prepared by twostage hot pressing from chemically co-precipitated raw materials synthesized from a mixture of main oxides with the amount of $\mathrm{Mn}_{2} \mathrm{O}_{3}$ required to obtain $\mathrm{Mn}$ concentrations of $0.01,0.1,0.3,1.0$, and $3.0 \%$ by mass. The product was hot-pressed for $30 \mathrm{~min}$ at $970{ }^{\circ} \mathrm{C}$ in vacuum $\left(10^{-4} \mathrm{~mm} \mathrm{Hg}\right)$ inside an $\mathrm{Al}_{2} \mathrm{O}_{3}$ mould under uniaxial pressure of $300 \mathrm{~kg} / \mathrm{cm}^{2}$. The second stage was completed at $1200^{\circ} \mathrm{C}$ during $20 \mathrm{~h}$ under pressure of $200 \mathrm{~kg} / \mathrm{cm}^{2}$ in $\mathrm{PbO}$ atmosphere. Samples were cut from bulk specimens, polished to thickness of $0.5 \mathrm{~mm}$ and furnished with fired (at $500{ }^{\circ} \mathrm{C}$ ) Au electrodes to measure dielectric permittivity and polarisation.

The complex dielectric permittivity $\varepsilon^{*}=\varepsilon^{\prime}-\mathrm{i} \varepsilon^{\prime \prime}$ at field intensity of $0.4 \mathrm{~V} / \mathrm{cm}$ was measured by a $4284 \mathrm{~A}$ HP precision LCR impedance analyser within the temperature range from $20^{\circ} \mathrm{C}$ to $350{ }^{\circ} \mathrm{C}$ in the frequency range between $100 \mathrm{~Hz}$ and $1 \mathrm{MHz}$ the temperature being changed at the rate of $0.6{ }^{\circ} \mathrm{C} / \mathrm{min}$. Polarisation hysteresis at the quasi-static limit was measured by Sawyer-Tower techniques.

In our previous paper [47], using A PANanalytical X'Pert PRO Xray diffraction instrument as well as a Zeiss EVO 50 SEM, we have successfully performed the X-ray diffraction and microstructure analysis for pure PLZT (8/65/35) samples and PLZT doped with $1 \%$ $\mathrm{Cu}, \mathrm{Mn}, \mathrm{Fe}, \mathrm{Co}$ or $\mathrm{Ni}$. In particular, it was found that XRD revealed a shift of diffraction maxima towards large angles, i.e. reduction of the pseudo-cubic lattice parameter $\mathrm{a}={ }^{3} \sqrt{ } \mathrm{V}_{\mathrm{c}}$ of PLZT 8/65/35 by admixtures of $\mathrm{Mn}, \mathrm{Fe}, \mathrm{Ni}$, Co. Furthermore, it was observed an asymmetric broadening of the diffraction maxima at medium and large angles. The appropriate analysis of the splitting of 200, 220, and 222 reflections of the $\mathrm{CuK}_{\alpha}$ radiation suggests a monoclinic distortion of the original pseudo-cubic cell. Nevertheless, it was in Mn impurity case the monoclinic distortion was relatively weak. Concerning SEM studies of the fashion Fracture Behaviour of the PLZT (8/65/35)+Mn (1\%), in Ref. [41] it was also reported the observed grains have multifaceted regular shapes with thin grain boundaries. Such SEM results suggest that the grain boundary influence on the dielectric properties is minimal.

\section{Results and discussion}

The main features of $\varepsilon^{\prime}(T)$ and $\varepsilon^{\prime \prime}(T, f)$ in the PLZT $8 / 65 / 35+\mathrm{X}$ wt.\% Mn compounds are shown in Fig. 1(a-i).

Fig. 1a shows the $\varepsilon^{\prime}(T)$ behaviour at different frequencies for undoped PLZT sample.

Fig. 1b illustrates the "boost" effect in $\varepsilon^{\prime \prime}(T)$, the way the "boost" of $\varepsilon^{\prime \prime}(\mathrm{T})$ at $300{ }^{\circ} \mathrm{C}$ is estimated (the values see in Table 1 ), the temperature range of $\varepsilon^{\prime \prime}(f) \sim 1 / \omega^{\mathrm{n}}$ determined by Maxwell-Wagner polarisation $(\mathrm{MW})\left(\mathrm{T}<=\sim 200^{\circ} \mathrm{C}\right)$ and $\mathrm{AC}$ conductivity $\left(\mathrm{T}>\sim 220^{\circ} \mathrm{C}\right)$. An appropriate overview of the manifestations of polarisation mechanisms in the behaviour of $\varepsilon^{\prime \prime}(T, f)$ curves is presented by 3D graphs in Fig. 1d, e and f. Behaviour of $\varepsilon^{\prime \prime}(f)$ at $260^{\circ} \mathrm{C}$ in Fig. $1 \mathrm{~h}$ and $\mathrm{i}$ is shown in bold the rest referring to $\mathrm{T}<200{ }^{\circ} \mathrm{C}$.

Pure PLZT (8/65/35) exhibits the classic relaxor behaviour (130 $\mathrm{Hz}-1 \mathrm{MHz}$ ), namely $\varepsilon^{\prime \prime}$ is increasing with the frequency (Fig. 1a, d, and $\mathrm{g}-$ the first column of Fig. 1).

As it was shown more than once, see for example [55], for undoped PLZT 8/65/35 ceramics the shape of $\varepsilon^{\prime}(T, f)$ is fully determined by relaxation of the polar nano-regions (PNR) and the appropriate peak temperature of $\mathrm{T}_{\mathrm{m}, \varepsilon}$ is well fitted by the VogelFulcher (VF) law. However, as follows from Fig. 1 (E), for Mndoped PLZT 8/65/35 the observed peaks $\varepsilon^{\prime}(\mathrm{T})$ depending not "purely" relaxor peaks.

Consequently, other polarisation mechanisms are starting to dominate the effect of which is displayed by the change of the depth of $\varepsilon^{\prime}$ dispersion (dd), decreasing $\varepsilon_{\max }$ and shift of $T_{m \varepsilon^{\prime}}$ to higher temperatures (Table 1, Fig. 1a, b, and c).

However, regardless to breaking the VF law in all PLZT (8/65/ 35) + Mn compounds the presence of PNR is detectable as indicated by growth of $\varepsilon^{\prime \prime}(f)$ with increasing high enough the frequency, e. g., to $f>400 \mathrm{kHz}$ in the case of PLZT $(8 / 65 / 35)+1.0 \mathrm{wt} \% \mathrm{Mn}$ (Fig. 1i).

The flat maximum on the $\varepsilon^{\prime \prime}(f)$ curve of the PLZT $(8 / 65 /$ $35)+0.1 \mathrm{wt} \%$ Mn compound (Fig. $1 \mathrm{~h}$ ) is related to Debye dispersion characterised by broad distribution of relaxation frequencies.

We have to note that Fig. 1e shows, the relaxor peaks are still persistent in the dielectric data. Namely, in narrow frequencies range $(400,125,50$ and $19 \mathrm{kHz})$ in Fig. 1 e) $\varepsilon$ “" $(\mathrm{T})$ dependencies and in temperature range $\sim 100-200{ }^{\circ} \mathrm{C}$ we can observe Debye like relaxation (red arrows and explanation in the figure), and the relaxor type peaks (blue arrows and explanation in figure) in the composition PLZT 8/65/35 + 0.1\% Mn. But the "pure" form of those peaks cannot be clearly distinguished; there is their clear coexistence and interaction, so they are not simple Debye and relaxor peaks. Thus it seems evident and clear the dielectric response consist of several processes: relaxor, Debye and MW, which can be found under certain $\mathrm{T}$ and f ranges, as follows from Fig. $1 \mathrm{~b}, \mathrm{e}, \mathrm{h}$.

Similar dispersion is also observed in compounds with 0.01 and $0.3 \mathrm{wt} \% \mathrm{Mn}$. The activation energy $\mathrm{E}_{\mathrm{a}}$ determined from $\varepsilon^{\prime \prime}(f)$ maximums and Cole-Cole diagrams is estimated to be $\approx 0.3-0.6 \mathrm{eV}$ (Table 1). Debye dispersion in these compounds is observed in the $1 \mathrm{kHz}-400 \mathrm{kHz}$ frequency range at temperatures from 70 to $190{ }^{\circ} \mathrm{C}$. The type of dispersion is also manifested as a maximum of $\varepsilon^{\prime \prime}(T)$ at $\mathrm{T}>\mathrm{T}_{\mathrm{m} \varepsilon^{\prime}}$ in the frequency range of $\cong 19-400 \mathrm{kHz}$ at temperatures from 110 to $150{ }^{\circ} \mathrm{C}$ (Fig. 1e, 3D view).

The $\mathrm{Me}-\mathrm{V}_{\mathrm{O}}$ dipoles are assumed to cause Debye dispersion in the $\mathrm{ABO}_{3}+\mathrm{Me}$ compounds ( $\mathrm{Me}=\mathrm{Mn}$, Fe, Co occupying the $\mathrm{B}$ sites of the lattice as acceptors). It is also applicable to a case our of $\mathrm{Mn}^{2+}$ $\mathrm{V}_{\mathrm{O}}$ and/or $\mathrm{Mn}^{3+}-\mathrm{V}_{\mathrm{O}}$ dipoles. Note that in the case of the much wellstudied $\mathrm{SrTiO}_{3}$, Mn can exist in a wide variety of oxidation states, it can be doped either as $\mathrm{Mn}^{2+}$ at the perovskite $A(\mathrm{Sr})$ or as $\mathrm{Mn}^{4+}$ at the $B$ (Ti) site or simultaneously at both the $A$ and $B$ sites in the corresponding oxidation states of $(2+)$ and $(4+)$, respectively [56,57]. In reduced Mn-doped $\mathrm{SrTiO}_{3}$ samples, EPR signals corresponding to $\mathrm{Mn}^{3+}-\mathrm{V}_{\mathrm{O}}$ centres have been also observed [58].

In the compound of $1.0 \mathrm{wt} \% \mathrm{Mn}$ the appropriate dependence of $\varepsilon^{\prime \prime}$ on the frequency is dominated by $\varepsilon^{\prime \prime}(f) \sim 1 / \omega^{\mathrm{n}}$ in the whole range of temperatures from $20^{\circ} \mathrm{C}$ to $300^{\circ} \mathrm{C}$ (Fig. 1i). A similar behaviour is 


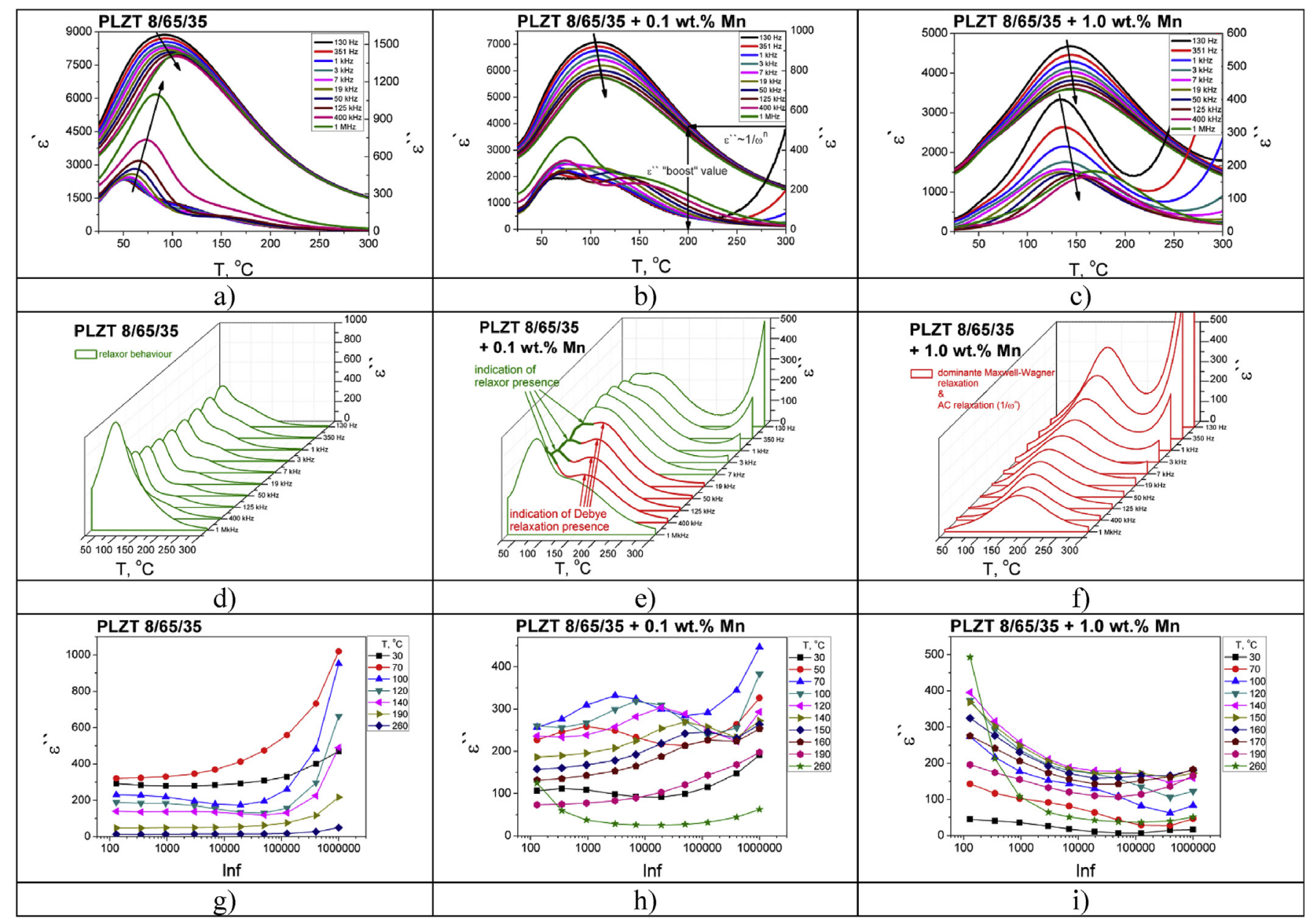

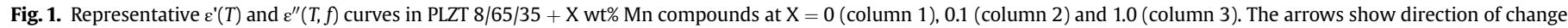
at increasing the frequency.

Table 1

Parameters of the $(T, f)$ for PLZT 8/85/35 + X wt\% Mn.

\begin{tabular}{|c|c|c|c|c|c|c|}
\hline $\mathrm{X}$ & $\varepsilon_{\text {max }}^{\prime} \mathrm{f}=130 \mathrm{~Hz}$ & 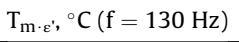 & dd for $\varepsilon_{\text {max }}^{\prime}$ & dd for $\varepsilon^{\prime}$ at $\mathrm{T}_{\varepsilon} \mathrm{a}^{\prime}+50{ }^{\circ} \mathrm{C}$ & $\mathrm{E}_{\mathrm{a}}, \mathrm{eV}$ (for Debye dispersion) & $\varepsilon^{\prime \prime}(\mathrm{T})$ "boost" $\Delta \varepsilon^{\prime \prime}\left(\mathrm{T}=300{ }^{\circ} \mathrm{C}\right)$ \\
\hline 0 & 9400 & 89 & 0,12 & 0,067 & - & 13 \\
\hline 0.01 & 8200 & 93 & 0,35 & 0,270 & 0.58 & 59 \\
\hline 0.1 & 7200 & 109 & 0,35 & 0,15 & 0.32 & 783 \\
\hline 0.3 & 6050 & 127 & 0,22 & 0,17 & 0.45 & 899 \\
\hline 1.0 & 4770 & 147 & 0,23 & 0,17 & 0.47 & 1769 \\
\hline
\end{tabular}

1. $\mathrm{T}_{\mathrm{m}}$ - maximum temperature of real part' of complex dielectric permittivity $\varepsilon^{*}=\varepsilon^{\prime}-\mathrm{i} \varepsilon^{\prime \prime}$, evaluated from $\varepsilon^{\prime}(T)$.

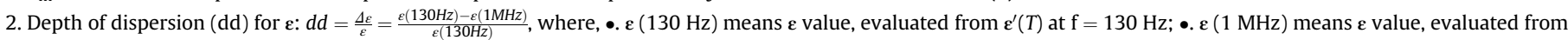
$\varepsilon^{\prime}(T)$ at $\mathrm{f}=1 \mathrm{MHz}$.

3. "Boost" of $\Delta \boldsymbol{\varepsilon}^{\prime \prime}$ at $300{ }^{\circ} \mathrm{C}$ (see Fig. 1b).

also observed in the PLZT $(8 / 65 / 35)+3.0 \mathrm{wt} \%$ Mn compound. However, two rather different mechanisms at similar $\varepsilon^{\prime \prime}(f) \sim 1 / \omega^{\mathrm{n}}$ behaviour should be distinguished. At temperatures $\mathrm{T}<=\sim 200{ }^{\circ} \mathrm{C}$ the $\varepsilon^{\prime \prime} \sim 1 / \omega$ dependence is determined by MW polarisation, while at $\mathrm{T}>\sim 220{ }^{\circ} \mathrm{C}$ by $\mathrm{AC}$ conductivity (the curves in bold at $260{ }^{\circ} \mathrm{C}$ for compounds with $X=0.1$ and $X=1.0$ in Fig. $1 \mathrm{~h}$ and $\mathrm{i}$ ). Note that oxygen vacancies involved in these both mechanisms have a different role in each of them.

It seems reasonable to expect the presence of oxygen vacancies at Mn concentration exceeding $>\sim 0.1 \mathrm{wt} \%$ and high enough temperatures $\left(\mathrm{T}>\sim 200-250{ }^{\circ} \mathrm{C}\right.$ ) being displayed in the dependence of $\varepsilon^{\prime \prime}(f) \sim 1 / \omega^{\text {n }}$ as the source of AC dispersion (see the $\varepsilon^{\prime \prime}(f)$ curves at $260{ }^{\circ} \mathrm{C}$ of compounds containing 0.1 and $1.0 \mathrm{wt} \% \mathrm{Mn}$ in Fig. $1 \mathrm{~h}$ and $\mathrm{i}$ ) and as "boost" effects on the $\varepsilon^{\prime \prime}(T)$ curves (Fig. 1b, Table 1 ).

At sufficiently high temperatures the vacancies $\left(V_{O}\right)$ may acquire high enough mobility and participate in conductivity [33]. Besides, the $\mathrm{V}_{\mathrm{O}}$ may show up as F-centres, it is, as suppliers of electrons to conductivity. The "boost" on $\varepsilon^{\prime \prime}(T)$ curves at T $>\sim 200^{\circ} \mathrm{C}$ and $\varepsilon^{\prime \prime} \sim 1 / \omega^{\mathrm{n}}$ AC dispersion of $\varepsilon^{\prime \prime}(f)$ in samples of $X=0.1,0.3,1.0$ and 3.0 related to $\mathrm{V}_{\mathrm{O}}$ is consistent with observations of other authors [54].

At lower temperatures $\left(\mathrm{T}<\sim 200{ }^{\circ} \mathrm{C}\right)$ the $\varepsilon^{\prime \prime} \sim 1 / \omega^{\mathrm{n}}$ relation is the manifestation of the Maxwell-Wagner dispersion. Their origin is related to the interfacial space charge accumulation (on a mesoscopic scale) at interface of two heterogeneities of essentially different dielectric permittivity and conductivity $\sigma$, it is - of different relaxation time $\tau=\varepsilon / \sigma$. So, to explain the nature of the 


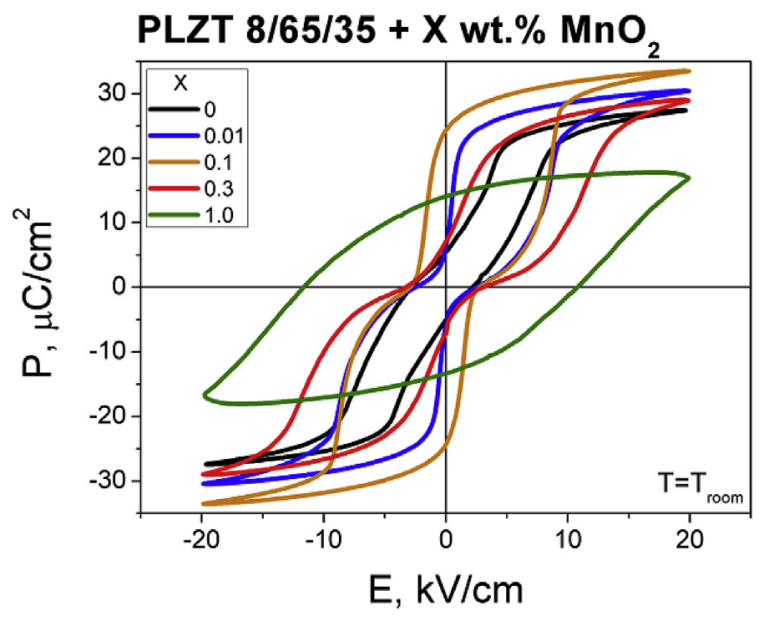

Fig. 2. Shapes of polarisation hysteresis $\mathrm{P}(E)$ loops of PLZT $(8 / 65 / 35)+\mathrm{X}$ wt.\% $\mathrm{Mn}$ compounds at different dopant concentrations.

MW dispersion it is necessary to disclose the nature of the heterogeneities and the space charge determining the difference of $\tau$.

With regard to heterogeneities it has to be mentioned that $3 d$ impurity ions affect structural homogeneity or heterogeneities, such as extended defects, short-range order of point defects, superlattice (ordering effects), and crystallographic shear plane defects [52-54]. Two kinds of the appropriate heterogeneities have to be considered in the case of PLZT $(8 / 65 / 35)+\mathrm{Mn}$ : grains and grain boundaries and the presence of a super-lattice (ordering effects).

SEM studies of the fracture mode behaviour of the PLZT (8/65/ $35)+$ Mn ceramics show the grains being of multifaceted regular shapes with thin grain boundaries. Furthermore, transgranular fractures rather often were observed in SEM images (fracture takes place through the volume of the grain). For that reason describing the heterogeneities in terms of extended defects and ordering is more reasonable. Note here, that the observed in Ref. [47] increase of the $\mathrm{I}_{210} / \mathrm{I}_{211}$ ratio of X-ray diffraction intensities with the admixture concentration can be interpreted by as presence of such super-lattice.

Relating the space charge to drift of oxygen vacancies $V_{O}$ under electrical field - $\mathrm{a}$ rather common explanation of the MW mechanism in some $\mathrm{ABO}_{3}$ compounds [54] - seems to be a reasonable assumption. However, if the "boost" correlating with $\mathrm{V}_{\mathrm{O}}$ (Table 1 ) is related to the increase of $V_{O}$ concentration, then absence of correlation between the $\mathrm{Mn}$ concentration (consequently, the concentration of $\mathrm{V}_{\mathrm{O}}$ ) and $\varepsilon^{\prime \prime}$ at $\mathrm{T}<200{ }^{\circ} \mathrm{C}$ points to a different role the vacancies play in MW dispersion, it is - they are not "free" to take part in drift or diffusion. The obtained results (comparing column 1 and column 2, Fig. 1) show Debye dispersion being replaced by Maxwell-Wagner dispersion with the growth of the Mn concentration wherefrom it is reasonable to conclude that $\mathrm{Mn}-\mathrm{V}_{\mathrm{O}}$ dipoles, growing in their concentration, start interacting and dipole clusters are formed. The latter - nanometre-size regions of a mesoscopic scale characterised by larger relaxation time constants - should be regarded as the dipoles contributing to the MW dispersion displayed by $1 / \omega^{\mathrm{n}}$ in the frequency range from $130 \mathrm{~Hz}$ to $1 \mathrm{MHz}$. In addition to the dispersion of dipole clusters corrections of the size of the clusters may be due to ordering effects brought by the presence of a super-lattice. As regards formation of the space charge, we assume that it is determined by interchange of $V_{O}$ between neighbouring dipoles - the oxygen octahedrons.

An essential aspect here to take into account is the Jahn-Teller effect related to $\mathrm{Mn}^{3+}$ ions (d4 configuration) manifested either as the dynamic, cooperative JTE or as field-induced effect linked to dipoles of Jahn-Teller ions [33,34]. These dipoles may be of two kinds: $\mathrm{Mn}^{3+}-\mathrm{V}_{\mathrm{O}}$ and $\mathrm{Mn}^{3+}$ ions pushed off the centre of the oxygen octahedron. This shift is a result of a smaller ion radius of $\mathrm{Mn}^{3+}$ (0.66 $\AA$ ) compared to 0.68 and $0.80 \AA$ of $\mathrm{Ti}^{4+}$ and $\mathrm{Zr}^{4+}$, respectively. Since the differences between the ion radii of $\mathrm{Mn}^{3+}$ and $\mathrm{Ti}^{4+}, \mathrm{Zr}^{4+}$ are not significant, the possibility of $\mathrm{Mn}^{3+}$ becoming an off-centre ion, as estimated, is rather low. Such possibility is higher in case of $\mathrm{Mn}^{4+}$ (not a Jahn-Teller ion) the radius of which is $0.53 \AA$.

It means that polar nano- and micro-size ferroelectric clusters and domains prompted by JTE may emerge in the studied compounds at high enough $\mathrm{Mn}$ concentrations $(\mathrm{X}>\sim=0.3 \mathrm{wt} \%)$ along with an increase of the Burns temperature $\mathrm{T}_{\mathrm{B}}$ (around $350{ }^{\circ} \mathrm{C}$ in pure PLZT). The rise of $T_{B}$ may substantially affect the number, the volume and interaction of PNR ultimately manifested as a significant enhancement of the volume of the polar phase, possibly as domains, at room temperature.

The most visible manifestations of the JTE in the studied PLZT: Mn compounds include 1) rhombohedra distortion [36], 2) shift of $\mathrm{T}_{\mathrm{m} \varepsilon^{\prime}}$ to higher values (Table 1 ), and 3) change of the shape of $\mathrm{P}(E)$ (Fig. 2). The presence of ferroelectric domains affecting the measurements of $\varepsilon(f, T)$ and contributing to dispersion is disputable. At high field intensities the polar phase is surely represented by domains while $\varepsilon$ measured at low field intensities (Fig. 1) points to the presence of PNR: $\varepsilon^{\prime \prime}$ increases with the frequency component in samples of all concentrations of the Mn admixture (Fig. $1 \mathrm{~h}$ and $1, i$ for $\mathrm{X}=0.1$ and $1.0 \mathrm{wt} \%$ ).

Currently, within the scope of the present study, the following hierarchy of manifestations and dominance of the dispersion mechanisms is assumed: with the growth of temperature and Mn concentration dispersion mechanisms gradually change each other:

1) from the Debye dispersion $\left(\mathrm{Mn}^{2+, 3+}-\mathrm{V}_{\mathrm{O}}\right.$ dipole individual reorientations at distances comparable with the size of the unit cell) to

2) Maxwell-Wagner dispersion: reorientation of $\mathrm{Mn}^{2+, 3+}-\mathrm{V}_{0}$ clusters, accompanied by and $\mathrm{V}_{\mathrm{O}}$ drift within heterogeneity to

AC conductivity includes mobile $\mathrm{V}_{\mathrm{O}}$ and electron conductivity. The change of one mechanism by other proceeds gradually, overlapping in time, the contribution of PNA becomes less detectable.

As the concentration of the Mn admixture grows the following changes of polarisation hysteresis loops $\mathrm{P}(E)$ occur (at room temperature, at field intensity of $30 \mathrm{kV} / \mathrm{cm}$ ): slim (restricted) loops in pure PLZT) $\rightarrow$ double loops (like anti-ferroelectric) at Mn concentrations of $0.01,0.1$ and $0.3 \mathrm{wt} \% \mathrm{Mn} \rightarrow$ rectangular (like ferroelectric) at $1.0 \mathrm{wt} \% \mathrm{Mn}$.

The double loops in different $\mathrm{ABO}_{3}$ compounds usually are explained by.

1) presence of the anti-ferroelectric (AFE) phase in the unpolarised state (which would be possible if the admixture affects the $\mathrm{X} / \mathrm{Y} / \mathrm{Z}$ ( $\mathrm{La} / \mathrm{Zr} / \mathrm{Ti}$ ) phase diagram of shifting the PLZT 8/65/35 $+\mathrm{Mn}$ structure from that relaxor phase to AFE phase), or

2) field-induced phase transition (e. g., relaxor $\rightarrow$ AFE),

3) ageing.

In recent study of ageing effects of PLZT compounds modified by $\mathrm{Mn}, \mathrm{Fe}$, and $\mathrm{Co}$ (to be published in forthcoming paper) it is found that double loops seen in Fig. 2 are not related to ageing. If the ageing effects could be excluded, presently no one of the first two can be preferred. A logical study of the electro-caloric effect has been started in attempt to choose one them.

Regarding the rectangular $\mathrm{P}(E)$ at $1 \mathrm{wt} \% \mathrm{Mn}$ the same as in case of double loops is suggested - the transition from relaxor to FE 
state being either field-induced or prompted by the added admixture (shift in $\mathrm{X} / \mathrm{Y} / \mathrm{Z}$ phase diagram).

The changes of $\mathrm{P}(E)$ seen in Fig. 2 are mainly determined by the Jahn-Teller effect. In the case of the sample containing $1.0 \mathrm{wt} \% \mathrm{Mn}$ the ideal rectangular shape of the polarisation loop specific to FE state is distorted by the high concentration of oxygen vacancies.

\section{Summary of the main changes induced by Mn admixture}

Essential modification in dielectric properties of electro-optical PLZT 8/65/35 ceramics induced by Mn doping include:

1) a shift of the $\varepsilon^{\prime}(T)$ maximum $T_{\varepsilon^{\prime} \text { max }}$ to higher temperatures along with a decline of the maximum value $\varepsilon_{\text {max }}^{\prime}$ and the change of dispersion characteristics, the depth of dispersion included, over the whole range of temperatures examined from $20^{\circ} \mathrm{C}$ to $400{ }^{\circ} \mathrm{C}$. The typical relaxor behaviour of unmodified PLZT compound complying with the Vogel-Fulcher law is restrained by Mn dopant and replaced by emerging Debye, Maxwell-Wagner and AC dispersion the dominant type of which depends on the temperature, the frequency of the electric field and the concentration of Mn admixture.

2) polarisation loops $\mathrm{P}(E)$ change with the concentration of $\mathrm{Mn}$ admixture from slim in the basic PLZT compound to double loops usually observed in anti-ferroelectrics at Mn content of $0.01,0.1$ and $0.3 \mathrm{wt} \% \mathrm{Mn}$, to rectangular as observed in ferroelectrics at $1.0 \mathrm{wt} \% \mathrm{Mn}$. ions:

The changes are explained as effects produced by $\mathrm{Mn}^{2+}, \mathrm{Mn}^{3+}$

1) dipoles of the $\mathrm{Mn}^{2+}$ and $\mathrm{V}_{\mathrm{O}}$ pairs determining Debye and Maxwell-Wagner polarisation:

2) $\mathrm{Mn}^{3+}$ is a Jahn-Teller ion responsible for Jahn-Teller distortion.

Oxygen vacancies, the concentration of which grows with the content of Mn doping (acceptor effect) and increasing of temperature, are of particular importance to three structural defects and respective dispersion mechanisms:

1) Debye dispersion at $\mathrm{T}<200{ }^{\circ} \mathrm{C}$ the oxygen vacancies $\mathrm{V}_{\mathrm{O}}$ being attached to $\mathrm{Mn}^{2+}$ and/or $\mathrm{Mn}^{3+}$ ions forming individual dipoles;

2) MW dispersion at $\mathrm{T}<200{ }^{\circ} \mathrm{C}$ being determined by $\mathrm{V}_{\mathrm{O}}$-induced extended heterogeneities and $\mathrm{V}_{\mathrm{O}}$ as a part of dipole clusters;

3) mobile oxygen vacancies manifested by $1 / \omega^{\mathrm{n}}$ dispersion of $A C$ conductivity at $\mathrm{T}>200^{\circ} \mathrm{C}$.

\section{Acknowledgements} IMIS2.

This work has been supported by Latvian state research program

\section{References}

[1] S. Vasala, M. Karppinen, Prog. Solid State Chem. 43 (2015) 1-36, http:// dx.doi.org/10.1016/j.progsolidstchem.2014.08.001.

[2] E. Grabowska, Appl. Catal. B 185 (2016) 97, http://dx.doi.org/10.1016/ j.apcatb.2015.12.035.

[3] Song A. Chae, Sung Sik Won, Hae Jin Seog, Aman Ullah, Chang Won Ahn, Il Won Kim, Curr. Appl. Phys. 16 (2016) 429-434.

[4] Sun-A. Yang, Byung-Hoon Kim, Min-Ku Lee, Sang-Don Bu, Gyoung-Ja Lee Curr. Appl. Phys. 16 (2016) 593-598.

[5] Ling Liu, Ni Qin, Dinghua Bao, Curr. Appl. Phys. 15 (2015) 748-752.

[6] Tae Hyun Kim, Seiji Kojima, Jae-Hyeon Ko, Curr. Appl. Phys. 14 (2014) $1643-1648$

[7] T.C. Asmara, X. Wang, I. Santoso, Q. Zhang, T. Shirakawa, D. Qi, A. Kotlov, M. Motapothula, M.H. Breese, T. Venkatesan, S. Yunoki, M. Rübhausen, Ariando, A. Rusydi, J. Appl. Phys. 115 (2014) 213706, http://dx.doi.org/
$10.1063 / 1.4878675$.

8] L. Grigorjeva, D.K. Millers, V. Pankratov, R.T. Williams, R.I. Eglitis, E.A. Kotomin, G. Borstel, Solid State Commun. 129 (2004) 691-696.

[9] E.A. Kotomin, R.I. Eglitis, G. Borstel, L. Grigorjeva, D. Millers, V. Pankratov, Nucl. Instrum. Method B 166-167 (2000) 299-304.

[10] M.M. Kuklja, E.A. Kotomin, O. Sharia, Yu.A. Mastrikov, J. Maier, Nucl. Instrum. Method B 326 (2014) 243-246.

[11] G.H. Haertling, C.E. Land, Hot-pressed (Pb, La) $\left(\mathrm{Zr}\right.$, Ti) $\mathrm{O}_{3}$ ferroelectric ceramics for electrooptic applications, J. Am. Ceram. Soc. 54 (1971) 1-11.

[12] K. Okazaki, K. Nagata, J. Am. Ceram. Soc. 56 (1973) 82-86.

[13] G.H. Haertling, PLZT electrooptic materials and applications-a review, Ferroelectrics 75 (1987) 25-55.

[14] M. Knite, A. Anspoks, M. Ozolinsh, Ferroelectrics 90 (1989) 203-207.

[15] K. Nonaka, M. Akiyama, C.N. Xu, T. Hagio, M. Komatsu, A. Takase, Jpn. J. Appl. Phys. 39 (9R) (2000) 5144.

[16] V.Y. Shur, E.L. Rumyantsev, G.G. Lomakin, O.V. Yakutova, D.V. Pelegov, A. Sternberg, M. Kosec, Ferroelectrics 314 (2005) 245-253.

[17] M. Knite, M. Ozolinsh, A. Sternberg, Ferroelectrics 94 (1989) 67-72.

[18] M. Knite, A. Kapenieks, A. Sternberg, M. Livins, Ferroelectrics 99 (1989) 71-74, http://dx.doi.org/10.1080/00150198908211272.

[19] A. Burkhanov, A. Shilnikov, A. Sternberg, Ferroelectrics 90 (1989) 39-43, http://dx.doi.org/10.1080/00150198908211268.

[20] M. Ishida, H. Matsunami, T. Tanaka, J. Appl. Phys. 48 (1977) 951-953.

[21] T. Kawaguchi, H. Adachi, K. Setsune, O. Yamazaki, K. Wasa, Appl. Opt. 23 (1984) 2187-2191.

[22] G.A. Petersen, J.R. McNeil, Thin Solid Films 220 (1992) 87-91.

[23] R. Thomas, S. Mochizuki, T. Mihara, T. Ishida, Thin Solid Films 443 (2003) $14-22$.

[24] M. Gaidi, A. Amassian, M. Chaker, M. Kulishov, L. Martinu, Appl. Surf. Sci. 226 (2004) 347-354

[25] A. Khodorov, M.J.M. Gomes, Thin solid films 515 (2006) 1782-1787.

[26] S. Dutta, A.A. Jeyaseelan, S. Sruthi, Thin Solid Films 562 (2014) 190-194.

[27] S.B. Desu, E.C. Subbarao, Ferroelectrics 37 (1981) 665-668.

[28] K.A. Müller, J. Phys. Fr. 42 (1981) 551-557, http://dx.doi.org/10.1051/jphys: 01981004204055100.

[29] L. Eyraud, P. Gonnard, B. Claudel, J. Am. Ceram. Soc. 73 (7) (1990) 1854-1856.

[30] L. Grigorjeva, D. Millers, A.I. Popov, E.S. Polzik, J. Lumin. 72 (1997) 672-674.

[31] A.I. Popov, E. Balanzat, Nucl. Instr. Meth. B 166 (2000) 305-308.

[32] A. Tkach, P.M. Vilarinho, A.L. Kholkin, Appl. Phys. Lett. 86 (2005) 172902.

[33] V.S. Vikhnin, E.A. Ruzanova, Bull. Russ. Acad. Sci. Phys. 71 (2007) 1347-1350.

[34] K.G. Bogdanova, A.R. Bulatov, V.A. Golenishchev-Kutuzov, R.I. Kalimullin, A.A. Potapov, Bull. Russ. Acad. Sci. Phys. 72 (8) (2008) 1159-1161.

[35] L. Zhang, E. Erdem, X. Ren, R.A. Eichel, Appl. Phys. Lett. 93 (2008) 202901.

[36] X. Zhou, J. Shi, C. Li, J. Phys. Chem. C 115 (2011) 8305-8311.

[37] S. Maletic, D. Maletic, I. Petronijevic, J. Dojcilovic, D.M. Popovic, Chin. Phys. B 23 (2014) 026102

[38] E. Blokhin, E. Kotomin, A. Kuzmin, J. Purans, R. Evarestov, J. Maier, Appl. Phys. Lett. 102 (2013) 112913.

[39] A.I. Popov, E.A. Kotomin, J. Maier, Nucl. Instr. Meth. B 268 (2010) 3084-3089.

[40] Yu.F. Zhukovskii,N. Pugno,A.I. Popov,C. Balasubramanian,S. Bellucci, J. Phys. Condens. Matter 19 (39) 395021

[41] M. Arrigoni, E. Kotomin, D. Gryaznov, J. Maier, Phys. Stat. Sol. (b) 252 (2015) 139-143.

[42] D. Gryaznov, S. Baumann, E.A. Kotomin, R. Merkle, J. Phys. Chem. C 118 (2014) 29542-29553.

[43] H. Donnerberg, Atomic simulations of electrooptic and magnetooptic oxide materials, in: Springer Tracts in Modern Physics, vol. 151, Springer, New York, 1999.

[44] V.V. Laguta, M.D. Glinchuk, A.M. Slipenyuk, I.P. Bykov, Phys. Solid State 42 (2000) 2258-2264.

[45] V.P. Savchyn, A.I. Popov, O.I. Aksimentyeva, H. Klym, Yu.Yu. Horbenko, V. Serga, A. Moskina, and I. Karbovnyk, Fiz. Nizk. Temp. 42, 760 (2016) [Low Temp. Phys. 42, No. 7 (2016)].

[46] O.I. Aksimentyeva, V.P. Savchyn, V.P. Dyakonov, S. Piechota, Y.Y. Horbenko, I.Y. Opainych, P.Y. Demchenko, A. Popov, H. Szymczak, Mol. Cryst. Liq. Cryst. 590 (2014) 35.

[47] L. Kundzina, M. Kundzins, K. Kundzins, A. Plaude, M. Livinsh, M. Antonova, V. Dimza, Ferroelectrics 436 (2012) 38-48.

[48] S. Dutta, N. Choudhary, P.K. Sinha, Ceram. Int. 33 (1) (2007) 13-20.

[49] R. Rai, S. Mishra, N.K. Singh, J. Alloys Compd. 487 (2009) 494-498.

[50] M.A. Mohiddon, K.L. Yadav, J. Phys. D. Appl. Phys. 40 (2007) 7540-7547.

[51] X. Ning, P.Y. Ping, W. Zhuo, J. Am. Ceram. Soc. 95 (3) (2012) 999-1003.

[52] T.R.N. Kutty, R. Balachandran, Mater. Chem. Phys. 13 (1985) 467-475.

[53] D. O'Neill, R.M. Bowman, J.M. Gregg, Appl. Phys. Lett. 77 (2000) 3078-3080.

[54] L. Qiao, X. Bi, CrystEngComm 13 (2011) 1693-1696.

[55] J. Banys, R. Grigalaitis, A. Mikonis, J. Macutkevic, P. Keburis, Ferroelectrics 405 (2010) 3-12, http://dx.doi.org/10.1080/00150193.2010.482881.

[56] D. Choudhury, S. Mukherjee, P. Mandal, A. Sundaresan, U.V. Waghmare, S. Bhattacharjee, R. Mathieu, P. Lazor, O. Eriksson, B. Sanyal, P. Nordblad, A. Sharma, S.V. Bhat, O. Karis, D.D. Sarma, Phys. Rev. B 84 (2011) 125124.

[57] D. Choudhury, Pramana 84 (2015) 987.

[58] D.V. Azamat, A. Dejneka, J. Lancok, V.A. Trepakov, L. Jastrabik, A.G. Badalyan, J. Appl. Phys. 111 (2012) 104119. 